\title{
Effect of stretching exercises vs. Kinesio Taping on postoperative neck discomfort following total thyroidectomy in postmenopausal women
}

\author{
DOI: https://doi.org/10.5114/pq.2019.89463
}

\author{
Samah Hosney Nagib1, Rania Nagy Karkousha², Engy Mohamed El Nahas ${ }^{3}$ \\ ${ }^{1}$ Department of Physical Therapy for Surgery, Faculty of Physical Therapy, Cairo University, Cairo, Egypt \\ ${ }^{2}$ Department of Basic Science, Faculty of Physical Therapy, Cairo University, Cairo, Egypt \\ ${ }^{3}$ Department of Physical Therapy for Women's Health, Faculty of Physical Therapy, Cairo University, Cairo, Egypt
}

Abstract

Introduction. Thyroidectomy is a surgical operation where head and neck extension position is prescribed in the surgical procedure, which may lead to postoperative neck pain and neck range of movement limitation. The study aimed to determine the effect of neck stretching exercises vs. neck Kinesio Taping on neck discomfort following total thyroidectomy.

Methods. A quasi experimental design was applied in the pre-test post-test study. Overall, 30 female patients after total thyroidectomy were included and randomly assigned into 2 equal groups. Group A received neck stretching exercises while group B received Kinesio Tape for posterior neck muscles; both groups were treated for 1 month after surgery. A universal goniometer was used to assess neck range of motion. The Neck Pain and Disability Scale questionnaire served to evaluate pain and disability. Results. There were statistically significant differences in both groups for pre- and post-treatment pain and neck range of motion. For neck range of motion, a statistically significant post-treatment difference was observed between the 2 groups in favour of group A, while for Neck Pain and Disability Scale scores, there was no statistically significant post-treatment difference between the 2 groups.

Conclusions. Both active neck stretching exercises and Kinesio Taping had a significant effect on pain and range of motion in neck discomfort following total thyroidectomy in postmenopausal women 1 month after treatment, while active neck stretching was more effective on neck range of motion than Kinesio Taping.

Key words: thyroidectomy, neck stretching exercises, Kinesio Tape, postmenopausal

\section{Introduction}

The occurrence of most thyroid diseases (hypothyroidism, nodular goitre, and cancer) is most elevated among postmenopausal and older women [1]. The rate of thyroid cancer continues to rise; it has been increasing by an average of $6.4 \%$ every year in the course of the recent 10 years, and thyroid cancer mortality has been expanding by $0.9 \%$ every year over a similar period [2].

Thyroidectomy is a surgical removal of all or part of the thyroid gland [3]. The most common complication following thyroidectomy is neck discomfort symptoms such as pain, stress and pressure in the neck, stiffness in the shoulder, and limited shoulder and neck range of motion (ROM) [4].

Distress side effects happen because the patient's neck is kept in a hyperextended position all along the operation. During the early postoperative period, patients were noted not to move their necks and to walk robotically, perhaps to block the aggravated neck pain and to secure the dissections [5].

A former study inspected the impact of active neck stretching exercises on postoperative neck discomfort following thyroidectomy and revealed that the intervention provided a significant improvement in postoperative neck discomfort compared with the control group [5]. Another study was performed to investigate the effect of cervical Kinesio Taping (KT) on patients after thyroidectomy; a significant impact on pain reduction was observed [6].
The purpose of this study was to determine the effect of active neck stretching exercises vs. neck KT on postoperative neck discomfort following thyroidectomy in postmenopausal women.

\section{Subjects and methods}

\section{Design}

A quasi experimental design was applied in the pre-test post-test study. The independent variable was neck discomfort syndrome, while the dependent variables included neck pain and ROM. The study was conducted between August 2017 and March 2019 and the data were collected twice, before and after treatment: immediately on the $1^{\text {st }}$ day after the surgery and 1 month later, after the treatment.

\section{Sampling}

A total of 30 female patients underwent total thyroidectomy and were willing to participate in the study. They were selected in the National Cancer Institute, Cairo, Egypt. Their age range was $45-55$ years. All participants were informed about the purpose of the examination. They were randomly assigned with the odd and even method into 2 equal groups. Group A received active neck stretching exercises, while group B received KT on posterior neck muscles. Exclusion criteria involved orthopaedic and rheumatic conditions of the neck and the patient's inability to cooperate.

Correspondence address: Samah Hosney Nagib, Department of Physical Therapy for Surgery, Faculty of Physical Therapy, Cairo University, 7 Ahmed Elziat Street, Bean Elsariat, El Dokki, Giza, Cairo, Egypt, e-mail: samah.hossny@pt.cu.edu.eg 


\section{Instrumentation}

Neck ROM was assessed with a universal goniometer, while the Neck Pain and Disability Scale (NPDS) questionnaire served to evaluate pain.

\section{Evaluation procedures}

Neck ROM was examined in a sitting position. The patient was asked to sit with her back straight and tied to the back of a wooden seat. The subject's ankles, knees, and hips were placed at right angles, and arms were folded over the chest. The ROMs of the cervical spine in flexion, extension, lateral flexion to each side, and right-left rotation were measured with a universal goniometer [7].

The NPDS questionnaire contains 20 questions. The patient answered to each item by using a $10-\mathrm{cm}$ visual analogue scale, extending between 0 (normal function) and 5 (severely restricted function). The questions figured out the sharpness of neck ache and its impact on occupational, recreational, social, and daily life activities in relation to emotional factors. The total score from the NPDS ranges from 0 to 100 , with higher scores demonstrating stronger effects of neck pain [8].

\section{Treatment procedures}

\section{Group A: neck stretching exercises}

The stretching exercise group learned how to conduct active neck stretching exercises from the $1^{\text {st }}$ post-thyroidectomy day. The patients were asked to do the following sequence: relax shoulders and neck sufficiently, look down, move face to the right, move face to the left, incline head to the right, incline head to the left, turn shoulders round and round, and finally slowly raise hands fully, then lower them.

The participants were to perform 3 repetitions of each stretching exercise with a 15-second sustain at the end of the range, and then turn back to the neutral position, 3 times per day (morning, afternoon, and late afternoon) for 1 month. They were also given an assigned stretching exercise pamphlet [5].

\section{Group B: Kinesio Taping}

The application of KT was performed immediately postoperative. While the patient was seated, a 5-cm Y-shaped strip was placed symmetrically over the posterior cervical extensors with a degree of tightness of $25 \%$, from the dorsal region (T1-T2) to the upper-cervical area (C1-C2). Each 'tail' of the bandage was attached to the skin to provide the cervical spine with contralateral flexion and rotation. Another strip was 5-cm wide and formed as a capital 'I'. It was applied perpendicularly to the Y-strip, over the midcervical area (C3-C6), with the cervical spine in flexion, aiming to exert tension to the posterior structures. The treatment was implemented for 2 sessions per week for 1 month [9].

\section{Statistical analysis}

The statistical analysis of the scores was performed with the SPSS software, version 16 (SPSS Chicago, USA). Unpaired $t$-test was utilized for comparing age, body mass index (BMI), and operating time in the sample; a similar test was performed to compare the groups. Paired $t$-test served to compare pre- and post-treatment mean scores for each group. The significance level was set at $p<0.05$.

\section{Ethical approval}

The research related to human use has complied with all the relevant national regulations and institutional policies, has followed the tenets of the Declaration of Helsinki, and has been approved by the authors' institutional review board at the Faculty of Physical Therapy, Cairo University.

\section{Informed consent}

Informed consent has been obtained from all individuals included in this study.

\section{Results}

Overall, 40 patients were screened for eligibility, 30 only satisfied the inclusion criteria and completed the study. They were randomly assigned into 2 groups ( $A$ and $B$ ). Figure 1 shows the flow chart of patients all through the study.

The unpaired $t$-test showed that there were no significant differences in the groups with reference to age $(p=0.864)$, BMI $(p=0.721)$, or operating time $(p=0.894)$. The demographic characteristics are presented in Table 1.

Table 2 demonstrates the neck ROM mean scores. A statistically significant difference was observed between preand post-treatment results in each group $(p=0.001)$. In both groups before treatment, there were no statistically significant differences, with the $p$ value of $0.450,0.238,0.189,0.334$, 0.334 , and 0.189 for neck flexion and extension, right side bending, left side bending, right rotation, and left rotation, respectively. Statistically significant differences were found for post-treatment ROM values in both groups $(p=0.001)$.

Table 3 presents the NPDS mean scores. There was a statistically significant difference for pre- and post-treatment results in each group $(p=0.000)$. In both groups before treatment and in both groups after treatment, no statistically significant differences were observed, with $p$ values of 0.827 and 0.670 , respectively.

\section{Discussion}

This study was conducted to compare the effect of active neck stretching exercises vs. KT on postoperative neck discomfort following total thyroidectomy. The results showed that there were statistically significant differences for both groups before and after treatment regarding pain and neck

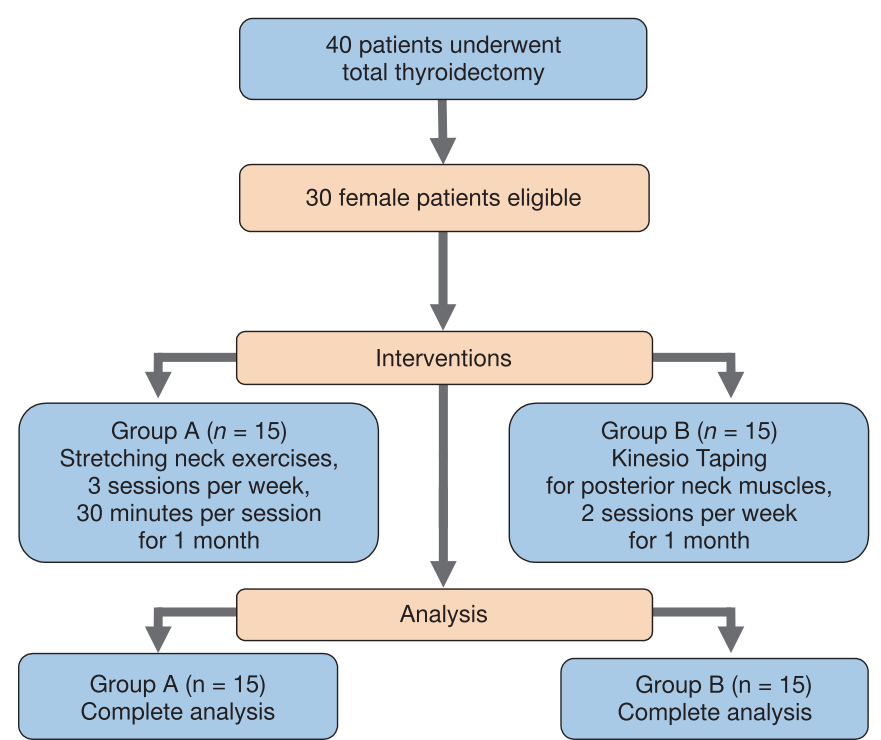

Figure 1. The flow chart of patients in the study 
Table 1. Demographic data of the patients

\begin{tabular}{|c|c|c|c|c|}
\hline \multirow{2}{*}{ General characteristics } & \multirow{2}{*}{$\begin{array}{l}\text { Group } \mathrm{A}(n=15) \\
\quad(\text { mean } \pm S D)\end{array}$} & \multirow{2}{*}{$\begin{array}{l}\text { Group B }(n=15) \\
\quad(\text { mean } \pm S D)\end{array}$} & \multicolumn{2}{|c|}{ Comparison } \\
\hline & & & $t$-value & $p$-value \\
\hline Age (years) & $51.2 \pm 5.9$ & $51.5 \pm 6.6$ & 0.2 & $0.9^{*}$ \\
\hline $\mathrm{BMI}\left(\mathrm{kg} / \mathrm{m}^{2}\right)$ & $26.5 \pm 2.7$ & $26.5 \pm 2.5$ & 0.4 & $0.7^{\star}$ \\
\hline Operating time (minutes) & $125.9 \pm 9.2$ & $125.4 \pm 9.4$ & 0.3 & $0.9^{*}$ \\
\hline
\end{tabular}

$\mathrm{BMI}$ - body mass index, * non-significant values

Table 2. Neck range of motion mean scores between and within groups

\begin{tabular}{|c|c|c|c|c|}
\hline Item & Group A & Group B & $t$-value & $p$-value \\
\hline Flexion (pre) & $30.9 \pm 2.0$ & $30.0 \pm 2.9$ & 0.8 & $0.4^{* *}$ \\
\hline Flexion (post) & $37.6 \pm 3.4$ & $33.73 \pm 3.7$ & 4.0 & $0.0^{*}$ \\
\hline$t$-value & 6.8 & 3.1 & & \\
\hline$p$-value & $0.0^{*}$ & $0.0^{*}$ & & \\
\hline Extension (pre) & $39.3 \pm 1.4$ & $39.1 \pm 2.0$ & 0.3 & $0.8^{* *}$ \\
\hline Extension (post) & $47.0 \pm 1.8$ & $44.4 \pm 2.4$ & 3.3 & $0.0^{*}$ \\
\hline$t$-value & 4.1 & 6.4 & & \\
\hline$p$-value & $0.0^{*}$ & $0.0^{*}$ & & \\
\hline Right side bending (pre) & $20.7 \pm 1.5$ & $20.4 \pm 1.1$ & 0.4 & $0.7^{* *}$ \\
\hline Right side bending (post) & $28.3 \pm 1.5$ & $25.7 \pm 2.4$ & 3.9 & $0.0^{*}$ \\
\hline$t$-value & 4.4 & 9.0 & & \\
\hline$p$-value & $0.0^{*}$ & $0.0^{*}$ & & \\
\hline Left side bending (pre) & $20.0 \pm 1.2$ & $20.1 \pm 1.2$ & 1.3 & $0.9^{\star *}$ \\
\hline Left side bending (post) & $27.3 \pm 2.5$ & $24.6 \pm 2.4$ & 3.7 & $0.0^{*}$ \\
\hline$t$-value & 9.9 & 6.1 & & \\
\hline$p$-value & $0.0^{*}$ & $0.0^{*}$ & & \\
\hline Right rotation (pre) & $50.9 \pm 2.6$ & $50.26 \pm 1.791$ & 0.7 & $0.5^{\star *}$ \\
\hline Right rotation (post) & $56.9 \pm 1.8$ & $53.93 \pm 3.081$ & 3.3 & $0.0^{*}$ \\
\hline$t$-value & 8.4 & 3.882 & & \\
\hline$p$-value & $0.0^{*}$ & $0.001^{*}$ & & \\
\hline Left rotation (pre) & $50.4 \pm 1.8$ & $50.3 \pm 1.8$ & 0.1 & $0.9^{* *}$ \\
\hline Left rotation (post) & $54.5 \pm 3.0$ & $51.4 \pm 2.4$ & 3.6 & $0.0^{*}$ \\
\hline$t$-value & 4.4 & 1.5 & & \\
\hline$p$-value & $0.0^{*}$ & $0.0^{*}$ & & \\
\hline
\end{tabular}

* significant values, ${ }^{* *}$ non-significant values

Table 3. Neck Pain and Disability Scale mean scores between and within groups

\begin{tabular}{|c|c|c|c|c|}
\hline & Group A & Group B & $t$-value & $p$-value \\
\hline Before treatment & $81.8 \pm 12.5$ & $81.1 \pm 13.4$ & 0.2 & $0.8^{\star \star}$ \\
\hline After treatment & $26.7 \pm 10.5$ & $27.3 \pm 12.2$ & 0.4 & $0.7^{* *}$ \\
\hline$t$-value & 11.2 & 13.9 & & \\
\hline$p$-value & $0.0^{*}$ & $0.0^{*}$ & & \\
\hline
\end{tabular}

${ }^{\text {* }}$ significant values, ${ }^{* *}$ non-significant values 
ROM. For neck ROM, a statistically significant difference was observed between the 2 groups after treatment in favour of group A, while for NPDS scores, there was no statistically significant difference between the 2 groups after treatment.

It was theorized that $\mathrm{KT}$ exerted its influence in many ways, such as restoring correct muscle function, decreasing congestion by stimulating the flow of blood and lymphatic fluid, diminishing pain by stimulating the neurological system, regaining malaligned joints, and providing immediate sensorimotor feedback with regard to functional skills [10]. Pain relief by KT use was proposed owing to pain modulation through the gate control theory [11] because it has been suggested that the tape stimulates neuromuscular pathways by intensifying afferent feedback through increasing mechanical receptors release to the spinal cord, which implies pain blocking $[12,13]$.

Also, in the context of the study results explanation, there are several reasons for reduced joint ROM, only one of which is muscular tightness, where muscles can become shortened through scarring or postural adaptation [14]. Stretching is purposive to improve joint ROM and flexibility, decrease muscle tension, increase circulation, and relieve muscle pain [15-17].

The study results go in agreement with those obtained by Genç et al. [6], who examined the effect of KT on pain and ROM after whiplash injury and declared that there was a statistically significant decline in pain scores and a statistically significant improvement in cervical ROM.

The outcomes are also in line with the observations presented by Ayhan et al. [18], who investigated the effect of neck stretching exercises after total thyroidectomy on neck pain and disability and reported a statistically significant reduction in pain and disability. Abd-El Mohsen and Ahmed [19] revealed that applying neck stretching exercises significantly improved the neck condition concerning neck pain and disability 1 week after total thyroidectomy.

On the other hand, Jang et al. [20] found that there was no significant difference determined between the stretching exercise group and the control one in terms of neck discomfort or ROM 3 months after thyroidectomy. The study results also disagree with Ayhan et al. [18], who found no significant differences between the stretching neck exercises group and the control group with regard to neck pain and disability or neck sensitivity and pain with neck movements 1 month after total thyroidectomy.

The study results did not go in line with the observations by Csapo and Alegre [21], who concluded that KT did not have any significant effect on muscle strength. Neither did they follow the findings by Gómez-Soriano et al. [22], who claimed that the application of KT in the gastrocnemius exerted no effect on the healthy muscle tone, extensibility, or strength.

\section{Limitations}

The authors are aware of the study limitations. Firstly, the investigation involved a limited number of patients. Secondly, few studies were performed on the treatment of neck syndrome following thyroidectomy.

\section{Conclusions}

The study results revealed statistically significant differences in both groups for pre- and post-treatment pain and neck ROM, while active neck stretching exercises were more effective for neck ROM improvement than KT.

\section{Disclosure statement}

No author has any financial interest or received any financial benefit from this research.

\section{Conflict of interest}

The authors state no conflict of interest.

\section{References}

1. Gietka-Czernel M. The thyroid gland in postmenopausal women: physiology and diseases. Prz Menopauzalny. 2017;16(2):33-37; doi: 10.5114/pm.2017.68588.

2. Howlader N, Noone AM, Krapcho M, Garshell J, Neyman N, Altekruse SF, et al. (eds.). SEER Cancer Statistics Review, 1975-2010. Bethesda: National Cancer Institute; 2013.

3. Liu ZW, Masterson L, Fish B, Jani P, Chatterjee K. Thyroid surgery for Graves' disease and Graves' ophthalmopathy. Cochrane Database Syst Rev. 2015;11:CD010576; doi: 10.1002/14651858.CD010576.pub2.

4. Kelly KA. Endocrine problems. In: Lewis SL, Dirksen SR, Heitkemper M, Bucher L, Harding MM (eds.), Medicalsurgical nursing: assessment and management of clinical problems, $9^{\text {th }}$ ed. St. Lewis: Mosby; 2013; 1189-1217.

5. Takamura Y, Miyauchi A, Tomoda C, Uruno T, Ito Y, Miya A, et al. Stretching exercises to reduce symptoms of postoperative neck discomfort after thyroid surgery: prospective randomized study. World J Surg. 2005;29(6):775779; doi: 10.1007/s00268-005-7722-3.

6. Genç A, GençV, Celik SU, Gokmen D, Tur BS. The effects of cervical kinesio taping on pain, range of motion, and disability in patients following thyroidectomy: a randomized clinical trial, preliminary results. Ann Phys Rehabil Med. 2018;61(Suppl.):e104; doi: 10.1016/j.rehab.2018. 05.222 .

7. Yankai A, Manosan P. Reliability of the universal and invented gravity goniometers in measuring active cervical range of motion in normal healthy subjects. Int $\mathrm{J}$ Appl Biomed Eng. 2009;2(1):49-53.

8. Wheeler A, Goolkasian P, Baird AC, Darden BV 2 nd. Development of the neck pain and disability scale. Item analysis, face, and criterion-related validity. Spine. 1999; 24(13):1290-1294; doi: 10.1097/00007632-19990701000004.

9. Kase K, Wallis J, Kase T. Clinical therapeutic applications of the Kinesio Taping method. Tokyo: Kinesio Taping Association International; 2013.

10. Thelen MD, Dauber JA, Stoneman PD. The clinical efficacy of kinesio tape for shoulder pain: a randomized, double-blinded, clinical trial. J Orthop Sports Phys Ther. 2008;38(7):389-395; doi: 10.2519/jospt.2008.2791.

11. Kneeshaw D. Shoulder taping in the clinical setting. J Bodyw Mov Ther. 2002;6(1):2-8; doi: 10.1054/jbmt. 2001.0233.

12. Muller M, Tsui D, Schnurr R, Biddulph-Deisroth L, Hard J, MacDermid JC. Effectiveness of hand therapy interventions in primary management of carpal tunnel syndrome: a systematic review. J Hand Ther. 2004;17(2):210-228; doi: 10.1197/j.jht.2004.02.009.

13. Williams S, Whatman C, Hume PA, Sheerin K. Kinesio taping in treatment and prevention of sports injuries: a meta-analysis of the evidence for its effectiveness. Sports Med. 2012;42(2):153-164; doi: 10.2165/11594 960-000000000-00000.

14. Phil P. Current concepts in muscle stretching for exercise and rehabilitation. Int J Sports Phys Ther. 2012;7(1): 109-119. 
15. Suzuki S, Hirano Y, Suzuki T. ID stretching, $2^{\text {nd }}$ ed. Tokyo: Miwa-Shoten; 2006.

16. Behm DG, Bambury A, Cahill F, Power K. Effect of acute static stretching on force, balance, reaction time, and movement time. Med Sci Sports Exerc. 2004;36(8): 1397-1402;doi:10.1249/01.MSS.0000135788.23012.5F.

17. Suzuki S. Testing of the effects of physical therapy on myofascial pain by imaging. J Jpn Phys Ther Assoc. 2005; 32(7):32-33.

18. Ayhan H, Tastan S, lyigün E, Oztürk E, Yildiz R, Görgülü $S$. The effectiveness of neck stretching exercises following total thyroidectomy on reducing neck pain and disability: a randomized controlled trial. Worldviews Evid Based Nurs. 2016;13(3):224-231; doi: 10.1111/wvn.12136.

19. Abd-El Mohsen SA, Ahmed NM. Effect of teaching patients neck stretching exercises on neck pain and disability following thyroidectomy. J Nurs Educ Pract. 2018; 8(1):107-113; doi: 10.5430/jnep.v8n1p107.

20. Jang JY, Chang Y-S, Kim EH, Moon JH, Son Y-I. Early neck exercises to reduce post-thyroidectomy syndrome after uncomplicated thyroid surgery: a prospective randomized study. J Korean Thyroid Assoc. 2014;7(1):7076; doi: 10.11106/jkta.2014.7.1.70.

21. Csapo R, Alegre LM. Effects of Kinesio ${ }^{\circledR}$ taping on skeletal muscle strength - a meta-analysis of current evidence. J Sci Med Sport. 2015;18(4):450-456; doi: 10.1016/j.jsams.2014.06.014.

22. Gómez-Soriano J, Abián-Vicén J, Aparicio-García C, Ruiz-Lázaro P, Simón-Martínez C, Bravo-Esteban E, et al. The effects of Kinesio taping on muscle tone in healthy subjects: a double-blind, placebo-controlled crossover trial. Man Ther. 2014;19(2):131-136; doi: 10.1016/j.math. 2013.09.002. 